\title{
Secretome analysis of the basidiomycete Phanerochaete chrysosporium grown on ammonia-treated lignocellulosic biomass from birch wood
}

\author{
Kiyoshi Sakuragi ${ }^{1,3} \cdot$ Chiaki Hori $^{1,4} \cdot$ Kiyohiko Igarashi $^{1,2} \cdot$ Masahiro Samejima $^{1}$
}

Received: 18 June 2018 / Accepted: 28 September 2018 / Published online: 1 November 2018

(c) The Author(s) 2018

\begin{abstract}
Ammonia pretreatment is a promising technique for enhancing enzymatic saccharification of lignocellulosic biomass. However, an enzymatic cocktail suitable for the breakdown of pretreated biomass samples is still being developed. The basidiomycete Phanerochaete chrysosporium is a well-studied fungus with regard to bioconversion of lignocellulosic biomass. In the present work, we analyzed proteins secreted by $P$. chrysosporium grown on untreated and ammonia-treated birch wood meal. Fungal growth, xylanase activity, and extracellular protease activity increased in the media containing the ammoniatreated biomass; however, cellulase production decreased compared to that observed in the untreated biomass. Secreted extracellular proteins were separated by two-dimensional electrophoresis and identified by liquid chromatography ion-trap mass spectrometry. Fifty-five spots corresponding to secreted proteins were chosen for further analysis. In the culture with ammonia-treated biomass, the relative concentration of a xylanase belonging to glycoside hydrolase (GH) family 11 increased, while acetyl xylan esterases belonging to carbohydrate esterase family 1 decreased. Moreover, GH family 10 xylanases were promoted proteolysis in the culture of ammonia-treated biomass, leading to the loss of family 1 carbohydrate-binding modules. These results indicated that $P$. chrysosporium produced enzymes related to the recognition of structural changes on xylan with de-acetylation and introduction of nitrogen by ammonia pretreatment of birch wood meal.
\end{abstract}

Keywords Phanerochaete chrysosporium $\cdot$ Secretome analysis $\cdot$ Lignocellulosic biomass $\cdot$ Ammonia pretreatment $\cdot$ Birch wood

Electronic supplementary material The online version of this article (https://doi.org/10.1007/s10086-018-1770-4) contains supplementary material, which is available to authorized users.

Masahiro Samejima

amsam@mail.ecc.u-tokyo.ac.jp

1 Department of Biomaterial Sciences, Graduate School of Agricultural and Life Sciences, The University of Tokyo, Tokyo 113-8657, Japan

2 VTT Technical Research Centre of Finland, P.O.Box 1000, Tietotie 2, 02044 VTT Espoo, Finland

3 Present Address: Energy Engineering Research Laboratory, Central Research Institute of Electric Power Industry, 2-6-1 Nagasaka, Yokosuka, Kanagawa 240-0196, Japan

4 Present Address: Graduate School and School of Engineering, Hokkaido University, North 13, West 8, Sapporo, Hokkaido 060-8628, Japan

\section{Introduction}

Lignocellulosic biomass, the most abundant renewable organic carbon source on earth, consists mainly of cellulose, hemicellulose, and lignin [1]. Appropriate conversion of biomass offers enormous potential for the production of biofuels and biochemicals.

Various pretreatment methods are used to enhance the enzymatic saccharification of lignocellulosic biomass [2]. Among them, one of the most promising approaches for lignocellulosic biomass from grass plants is pretreatment with liquefied ammonia, and this methodology has been extensively investigated [3-5]. The ammonia cleaves ester bonds in lignocellulosic biomass and generates amides [6, 7]. It has been demonstrated that ammonia pretreatment also alters the polymorphic form of crystalline cellulose with a low water content, transforming the natural crystalline form (cellulose I) to cellulose $\mathrm{III}_{\mathrm{I}}[8]$, which is far more susceptible to enzymatic degradation [9]. Moreover, we have recently reported 
that ammonia pretreatment is effective for improving enzymatic saccharification of not only grass biomasses but also hardwood biomasses with high xylan and low lignin contents such as birch wood and willow wood [10]. Nevertheless, searching for effective enzymes for the conversion of ammonia-treated hardwood biomass is still under development.

Wood-decay fungi are omnipotent degraders of lignocellulosic biomass and the basidiomycete Phanerochaete chrysosporium has been one of the best-studied examples [11-13]. P. chrysosporium produces a variety of extracellular enzymes including glycoside hydrolases (GHs), carbohydrate esterases (CEs) and oxidative enzymes with auxiliary activities (AAs) to degrade lignocellulosic biomass [14-18]. The sequenced genome of $P$. chrysosporium has revealed many genes that encode extracellular enzymes [19], and the results involving GHs, CEs, and AAs have been deposited into the Carbohydrate-Active enZymes (CAZymes) database [20]. Moreover, extensive proteomic analysis of extracellular proteins, or the secretome, has been performed to map the lignocellulolytic system of the fungus [14, 16, 18, 21, 22].

In the present study, we aimed to examine the effect of ammonia treatment on the extracellular proteins of $P$. chrysosporium to degrade lignocellulosic biomass by performing a comparative secretome analysis of $P$. chrysosporium grown on untreated or ammonia-treated lignocellulosic biomass from birch wood.

\section{Materials and methods}

\section{Preparation and chemical analysis of biomass}

The preparation and chemical analysis of untreated or ammonia-treated birch wood meal were previously reported [10]. In brief, a birch wood block was milled, and then sieved to obtain 40-mesh-passed meal. The wood meal was Soxhlet extracted with benzene-ethanol $(2: 1 \mathrm{v} / \mathrm{v})$ and used for experiments as untreated biomass (UB). UB was treated with liquefied ammonia at $140{ }^{\circ} \mathrm{C}$ for $1 \mathrm{~h}$ and used for experiments as ammonia-treated biomass ( $\mathrm{AB})$.

\section{Cultivation of Phanerochaete chrysosporium and enzyme assays}

The cultivation of Phanerochaete chrysosporium and enzyme assays were performed according to the method in our previous paper [23] with slight modifications. In brief, $P$. chrysosporium strain K-3 [24] was cultivated in Kremer and Wood medium [25] for 3 days with $2.0 \%$ (w/v) UB or $\mathrm{AB}$ from birch wood as the sole carbon source. The media were sterilized by autoclaving at $121{ }^{\circ} \mathrm{C}$ for 20 min before inoculation. The fungal growth and protein concentration were determined daily. To evaluate fungal growth, $1 \mathrm{~mL}$ cultures were collected in a measuring tube and left to stand for $30 \mathrm{~min}$; the volume of sediment was used as a representative metric for the growth of fungal mycelia. The protein concentration of the culture was determined by Bradford assay (Bio-Rad Laboratories, Inc., California, US). Avicel (Funakoshi Co., Ltd., Tokyo, Japan), xylan from birch (Sigma-Aldrich Co., Missouri, US), and azoalbumin (SigmaAldrich Co.) were used as a substrate for assaying cellulase, xylanase and protease activities of culture. The amount of reducing sugar released by enzymatic reactions was measured using the $p$-hydroxybenzoic acid hydrazide (PHBAH; Wako Pure Chemical Industries, Ltd.) method [26, 27]. One unit of cellulase and xylanase activities were defined as the amount of enzyme required to release $1 \mu \mathrm{mol}$ reducing sugar per min under the assay conditions using a predetermined standard curve obtained with glucose and xylose, respectively. One unit of protease activity was defined as the amount of enzyme required for release of $0.001 \mathrm{Abs}$ at $335 \mathrm{~nm}$ per min under the assay conditions. Each conversion data point represents the mean of three measurements with the standard deviation. Statistically significant differences between the two series were assessed by Student's $t$ test or Aspin-Welch's $t$ test following an $F$ test assessment of variance.

\section{Separation and identification of proteins from Phanerochaete chrysosporium}

The separation and identification of proteins from $P$. chrysosporium have been described in detail [23]. In brief, the proteins from culture were separated by two-dimensional electrophoresis (2DE). The stained 2DE gels were scanned and individual protein spots on different gels were matched and quantified. Fifty-five spots of protein were digested by trypsin and analyzed by ultra-high-performance liquid chromatography-mass spectrometry. The peptides were identified by an in-house-licensed mascot search engine (Matrix Science K. K., London, UK) with 10,048 annotated gene models from the $P$. chrysosporium version 2.0 genome database (http://genome.jgi-psf.org/Phchr1/Phchr1.home.html) [23]. The obtained amino acid sequences were analyzed by a BLASTP search against the NCBI non-redundant database with default settings to confirm gene function [23].

\section{Results}

\section{Fungal growth, protein concentration, and enzymatic activity}

P. chrysosporium was cultivated in synthetic media containing the biomass either with $\mathrm{AB}$ and UB. As shown in Fig. 1a, the mycelial volume constituted $0.1 \mathrm{~mL}$ of the 


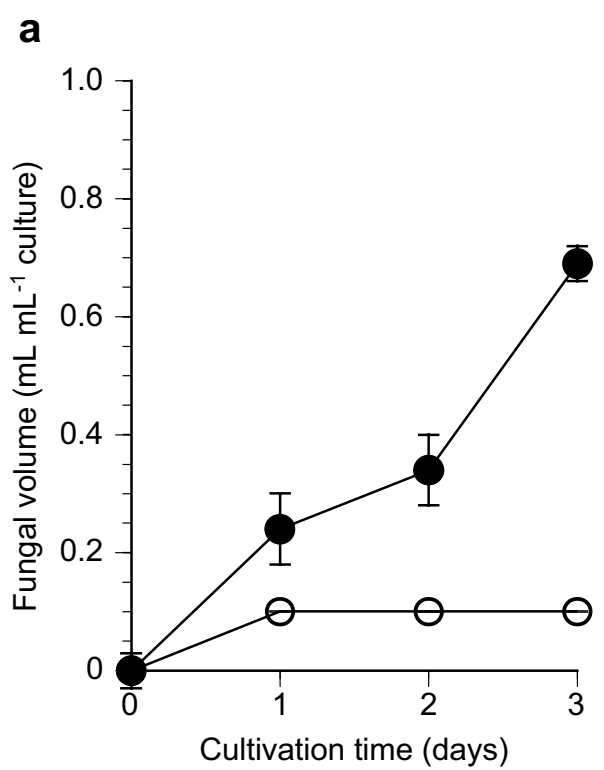

Fig. 1 Fungal growth and extracellular protein concentration of $P$. chrysosporium. a Fungal growth and $\mathbf{b}$ extracellular protein concentration of $P$. chrysosporium cultivated for 3 days in synthetic medium containing $2.0 \%(\mathrm{w} / \mathrm{v}) \mathrm{UB}$ (white circle) and $2.0 \%(\mathrm{w} / \mathrm{v}) \mathrm{AB}$ (black circle) as carbon sources. The mycelium volume per $1 \mathrm{~mL}$ of culture filtrate was measured as described in Materials and Methods. Protein

$1 \mathrm{~mL}$ UB culture on day 1 , and it remained at this level until day 3. Conversely, the mycelial volume increased remarkably in the $1 \mathrm{~mL} \mathrm{AB}$ culture, reaching $0.7 \mathrm{~mL}$ after 3 days $(p<0.01)$. In the UB culture, $1.2 \times 10^{-2} \mathrm{~g} \mathrm{~L}^{-1}$ of extracellular protein was secreted after 3 days of cultivation, compared to $0.6 \times 10^{-2} \mathrm{~g} \mathrm{~L}^{-1}$ in the $\mathrm{AB}$ culture (Fig. 1b). Although the changes in protein concentration of the cultures were not significantly different after 3 days of cultivation ( $p=\mathrm{n}$. s.), ammonia pretreatment greatly enhanced the growth of $P$. chrysosporium.

Cellulase, xylanase, and protease activity in the 3-day culture filtrates were measured and compared (Fig. 2). In the UB culture, $1.6 \mathrm{U} \mathrm{L}^{-1}$ of cellulase activity was measured after 3 days of cultivation, compared to $0.95 \mathrm{U} \mathrm{L}^{-1}$ in the AB culture (Fig. 2a). The specific activity of cellulase (activity/mg of total proteins) between $\mathrm{AB}$ and UB cultures was not significantly different $(p=\mathrm{n}$. s.). This may be because the major proteins secreted by $P$. chrysosporium are cellulases. On the other hand, the specific activity of xylanase and protease were markedly increased in the $A B$ culture compared to the UB control culture. Xylanase and protease activity increased 7.8- and 2.2-fold in the $A B$ culture compared to the UB control culture $(p<0.01)$. b

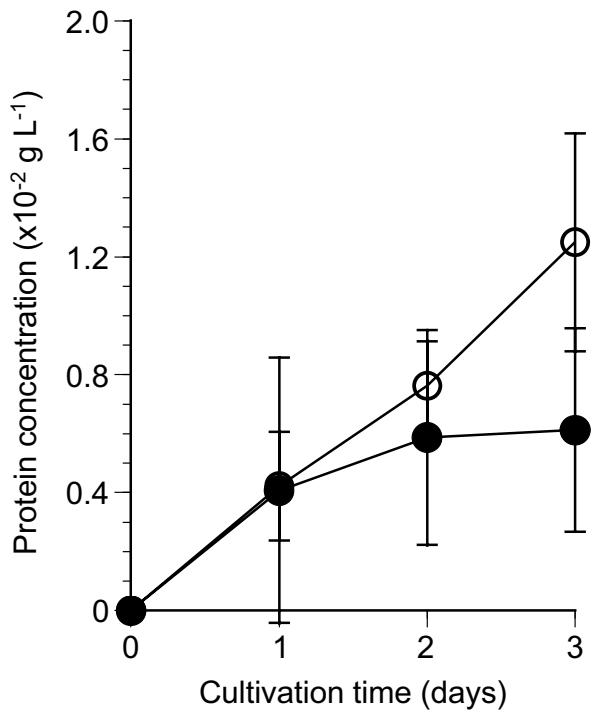

concentration of the culture filtrate was estimated by the Bradford method. $U B$ untreated birch wood meal, $A B$ ammonia-treated birch wood meal. Each data point represents the mean \pm standard deviation (SD) of three replicates. Where the error bars are not visible, they fit within the symbols

\section{Secretome analysis of proteins}

Extracellular proteins in the culture filtrates were separated by $2 \mathrm{DE}$ (Fig. 3). For both UB and AB filtrates, most of the protein spots focused at a $\mathrm{p} I$ of $4.5-5.5$, although their molecular masses ranged from 37 to $100 \mathrm{kDa}$. Of these spots, 55 spots were subjected to LC-MS/MS analysis (Table 1). These proteins were selected on the basis of the amount of protein and the sharpness of the spot. Most of the proteins were classified as CAZymes such as GHs (34 spots), CEs (10 spots), and AAs (3 spots). In addition, four thaumatin-like $(t h n)$ proteins and one aldose 1-epimerase (ale 1$)$ were detected. Protein functional analysis showed that many of the proteins were cellobiohydrolases and endoglucanases participate in cellulose degradation, as well as xylanases and accessory enzymes participate in xylan degradation $[14,16,18,21-23,28]$. Spot numbers $5,7,9,10,11,12,19,22,24,30,35,48$, and 52 were identified in both the UB and $\mathrm{AB}$ cultures. The major spots corresponded to cellobiohydrolases (Cel6A: spot 5; Cel7C: spots 11, 12, and 13; and Cel7D: spots 7 and 9), endoglucanases (Cel5A: spot 4; and Cel5B: spot 2), and xyloglucanase (Xgh74B: spot 31). 
Fig. 2 Comparison of cellulase, xylanase, and protease activities in $\mathrm{UB}$ and $\mathrm{AB}$ cultures after 3 days. Enzyme activity was measured in sodium acetate (pH 5.0) at $30^{\circ} \mathrm{C}$. a Avicel and b xylan from birch wood were used as substrates to measure enzyme activity in the UB and $\mathrm{AB}$ cultures. The newly formed reducing ends were estimated using the PHBAH method [26, 27] with some modifications. c Azoalbumin was used as a substrate. $A_{335 \mathrm{~nm}}$ of the reaction was measured. $U B$ untreated birch wood meal, $A B$ ammoniatreated birch wood meal.

Each data point represents the mean \pm standard deviation (SD) of three replicates. Statistical significance was determined using Student's or Welch's $t$ test $(* p<0.01 ; n . s$. not significant) a

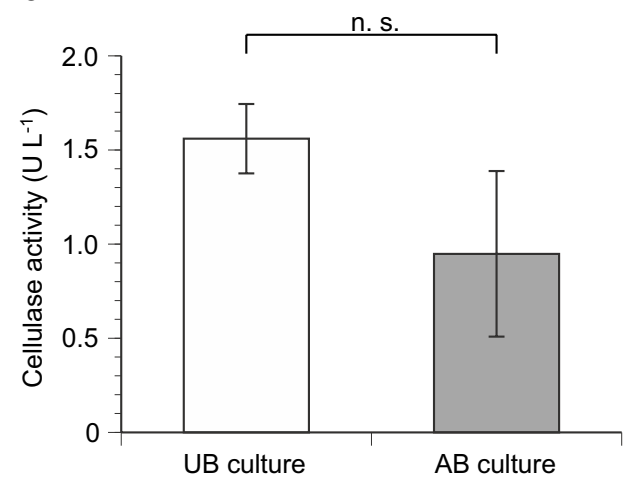

C

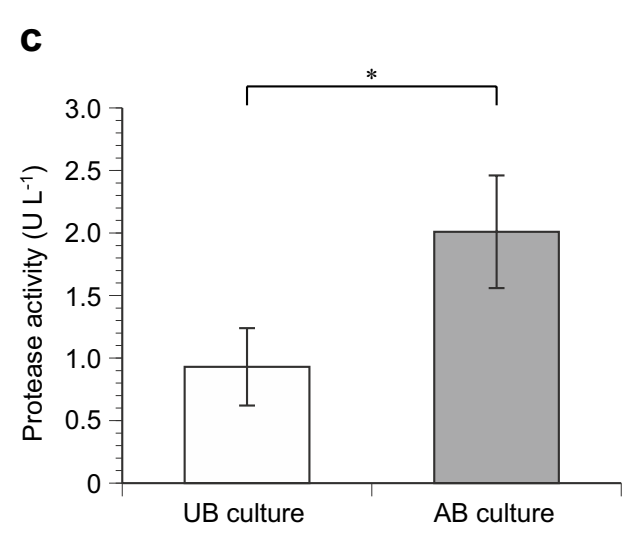

b

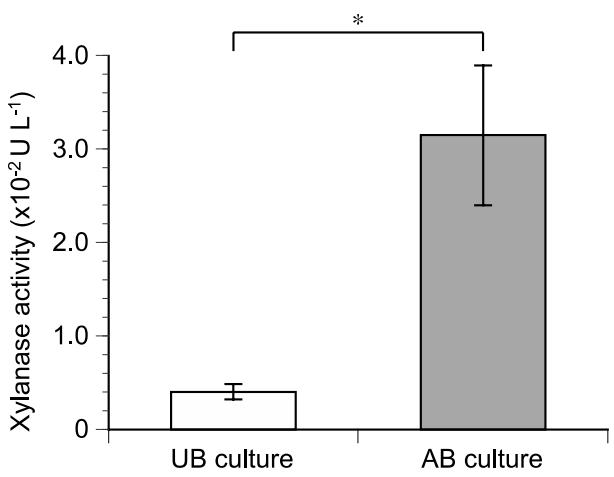

To investigate the effects of ammonia pretreatment on protein expression ratios, the normalized average volume of each protein spot in the $\mathrm{AB}$ culture was compared to that of the corresponding spot in the UB culture. For measured total protein in 2DE, 49\% (UB culture) and 51\% (AB culture) protein were identified. Cellobiohydrolases of GH family 7 were the most common extracellular proteins in both UB and $A B$ cultures, accounting for $40 \%$ of total protein. In the $\mathrm{AB}$ culture, 10 protein spots exhibited more than double the normalized average volume compared to the corresponding spots in the UB culture (Table 2). Among them, both spot 22 assigned to the GH family 11 xylanase (Xyn11B) and spot 23 of the proteolytic product derived from Xyn11B were remarkably enhanced in the $\mathrm{AB}$ culture compared to that in the UB culture. In contrast, six other protein spots in the $\mathrm{AB}$ culture showed less than $50 \%$ of the volume of the corresponding spots in the UB culture (Table 3). Spot 20 assigned to the GH family 10 xylanase (Xyn10C) was decreased in the $\mathrm{AB}$ culture, while spot 19 of the proteolytic product derived from Xyn10C was increased in the AB culture. In addition, it was notable that both Xyn10C (spot 20) and Xyn11B (spot 22) have a type I carbohydrate-binding module (CBM I) connected to the catalytic domain by a linker region, while any fragment assigned to CBM I was not detected from their proteolytic products corresponding to spot 19 and spot 23 with a lower molecular weight. A part of Xyn10C (spot 20) and Xyn11B (spot 22), therefore, may have been proteolytically degraded in the $\mathrm{AB}$ culture (Table S1, S2 and Fig. S1, S2).

\section{Discussion}

Ammonia pretreatment is particularly effective for improving the enzymatic saccharification of lignocellulosic biomass from grass plants [3-5]. In addition, we have recently reported that ammonia pretreatment is also effective for improving the enzymatic saccharification of hardwood biomasses such as birch wood with high xylan and low lignin contents [10]. The biomass recovery after ammonia pretreatment of birch wood meal was $99 \%$ and this pretreatment did not change the neutral sugar and lignin contents, while the content of nitrogen increased and the content of acetyl group decreased after ammonia pretreatment, suggesting that the acetyl substitution of xylan was eliminated by the cleavage of ester linkages during ammonia pretreatment [10].

In the present study, we found that whereas protein secretion by $P$. chrysosporium was depressed in the $\mathrm{AB}$, fungal growth was higher in the AB culture than in the UB culture. Although we must consider adsorption of enzymes to biomass residue, the above-mentioned finding indicated improved fungal digestion of the ammonia-treated biomass 
Fig. 3 Two-dimensional electrophoresis (2DE) of the UB and $A B$ cultures stained with Coomassie brilliant blue. a UB; b AB. P. chrysosporium was cultivated in synthetic medium containing $2.0 \%(\mathrm{w} / \mathrm{v}) \mathrm{UB}$ or $2.0 \%(\mathrm{w} / \mathrm{v}) \mathrm{AB}$ for 3 days. An aliquot $(100 \mu \mathrm{g})$ of extracellular protein from each sample was separated as described in "Materials and methods". The horizontal axis of the gel spans pH 4-7, and the vertical axis spans $250-10 \mathrm{kDa}$. Spot numbers correspond to the proteins in Table 1
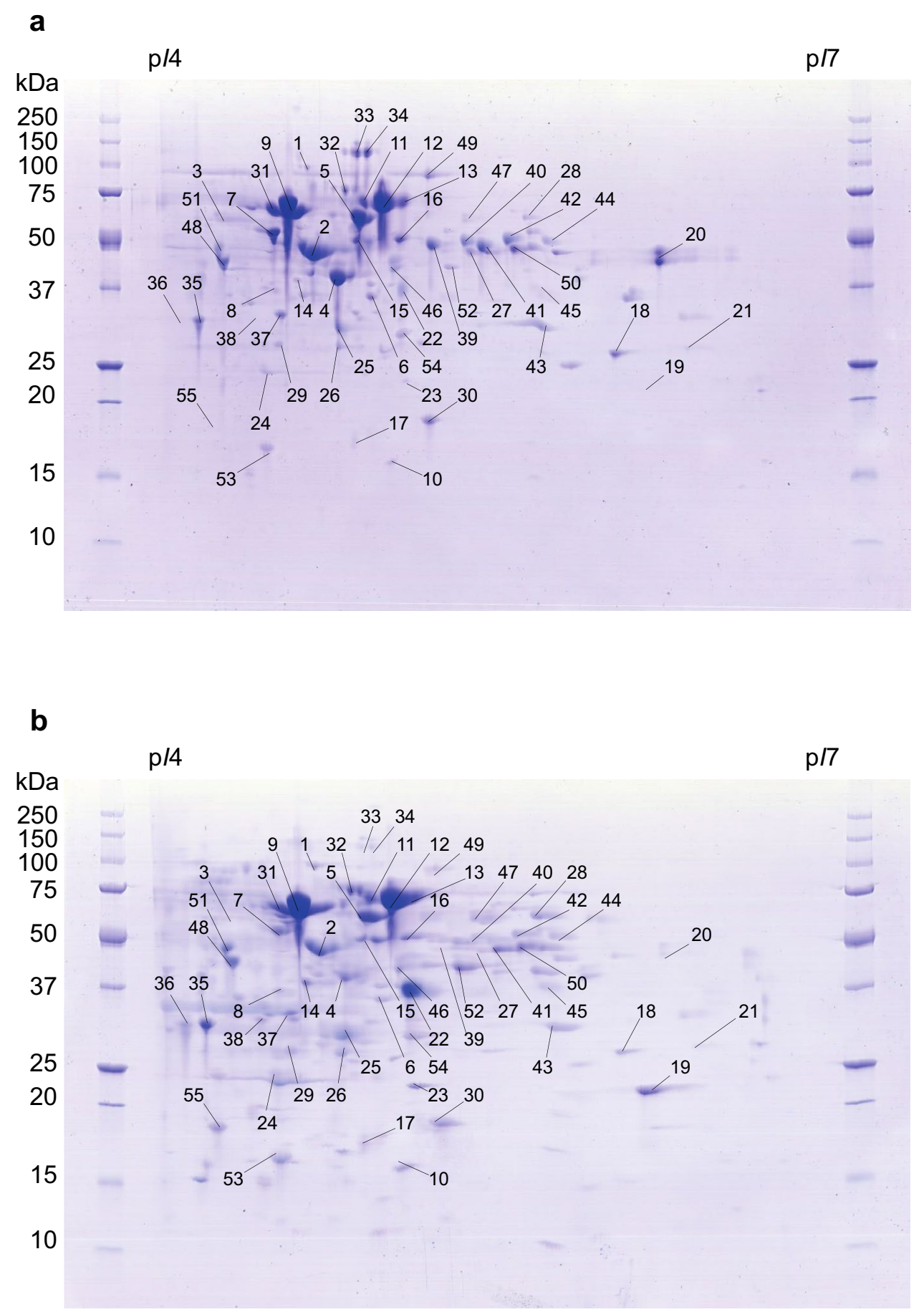

and catabolite repression of overall protein secretion during biomass degradation. Thus, this ammonia pretreatment process effectively enhances the hydrolysis of lignocellulosic biomass from birch wood.

There has been great interest in finding an optimal enzyme that hold a key role in biomass degradation can not only enable the supplementation of commercially available enzyme mixtures, but also the design of tailor-made enzyme cocktails that can be optimized for each substrate [30, 31]. In the present study, we used comparative secretome analysis to examine the effect of ammonia pretreatment on the levels of proteins secreted by $P$. chrysosporium grown on birch wood meal.

It is known that the concentration of nitrogen is the critical parameter for the production of lignin decomposition enzymes in $P$. chrysosporium [32]. However, since we cultivated $P$. chrysosporium in Kremer and Wood medium [25] containing a high level of nitrogen source, detection 
Table 1 Proteins secreted by $P$. chrysosporium after cultivation with untreated or ammonia-treated birch wood meal

Spot number Score $^{\mathrm{a}}$ Protein $\mathrm{ID}^{\mathrm{b}}$ Function (gene or domain) Protein family $\mathrm{CBM}^{\mathrm{c}} \quad \mathrm{Th} \mathrm{Mw}^{\mathrm{d}} \quad \mathrm{Th} \mathrm{p}^{\mathrm{d}} \quad$ Sequence coverage

(\%)

\begin{tabular}{|c|c|c|c|c|c|c|c|c|}
\hline 1 & 830 & 129849 & Glucan $\beta$-glycosidase $($ gly $3 B)$ & GH 3 & - & 87.142 & 4.72 & 36 \\
\hline 2 & 336 & 4361 & Endo- $\beta$-1,4-glucanase (cel5B) & GH 5 & $\mathrm{~N}$ & 49.730 & 6.21 & 17 \\
\hline 3 & 308 & 5115 & $\beta$-Mannanase $(\operatorname{man} 5 C)$ & GH 5 & $\mathrm{~N}$ & 41.058 & 4.27 & 10 \\
\hline 4 & 845 & 6458 & Endo- $\beta$-1,4-glucanase (cel5A) & GH 5 & $\mathrm{~N}$ & 39.856 & 5.04 & 49 \\
\hline 5 & 989 & 133052 & Cellobiohydrolase II (cel6A) & GH 6 & $\mathrm{~N}$ & 48.967 & 5.04 & 41 \\
\hline 6 & 343 & 133052 & Cellobiohydrolase II (cel6A) & GH 6 & $\mathrm{~N}$ & 48.967 & 5.04 & 30 \\
\hline 7 & 299 & 137372 & Cellobiohydrolase 58 (cel7D) & GH 7 & $\mathrm{C}$ & 59.497 & 4.96 & 25 \\
\hline 8 & 416 & 137372 & Cellobiohydrolase 58 (cel7D) & GH 7 & $\mathrm{C}$ & 59.497 & 4.96 & 34 \\
\hline 9 & 2046 & 137372 & Cellobiohydrolase 58 (cel7D) & GH 7 & $\mathrm{C}$ & 59.497 & 4.96 & 52 \\
\hline 10 & 224 & 137372 & Cellobiohydrolase 58 (cel7D) & GH 7 & $\mathrm{C}$ & 59.497 & 4.96 & 19 \\
\hline 11 & 1326 & 127029 & Cellobiohydrolase $62(\mathrm{cel} 7 \mathrm{C})$ & GH 7 & $\mathrm{C}$ & 56.128 & 5.03 & 54 \\
\hline 12 & 2010 & 127029 & Cellobiohydrolase $62(\mathrm{cel} 7 \mathrm{C})$ & GH 7 & $\mathrm{C}$ & 56.128 & 5.03 & 55 \\
\hline 13 & 1448 & 127029 & Cellobiohydrolase $62(\mathrm{cel} 7 \mathrm{C})$ & GH 7 & $\mathrm{C}$ & 56.128 & 5.03 & 50 \\
\hline 14 & 683 & 127029 & Cellobiohydrolase 62 (cel7C) & GH 7 & $\mathrm{C}$ & 56.128 & 5.03 & 45 \\
\hline 15 & 1173 & 138345 & Endo- $\beta-1,4$-xylanase (xyn10A) & GH 10 & $\mathrm{~N}$ & 44.065 & 5.21 & 55 \\
\hline 16 & 409 & 138345 & Endo- $\beta-1,4$-xylanase (xyn10A) & GH 10 & $\mathrm{~N}$ & 44.065 & 5.21 & 55 \\
\hline 17 & 498 & 7045 & Endo- $\beta-1,4$-xylanase $(x y n 10 C)$ & GH 10 & $\mathrm{~N}^{\mathrm{e}}$ & 31.213 & 6.89 & 42 \\
\hline 18 & 962 & 7045 & Endo- $\beta-1,4$-xylanase $(x y n 10 C)$ & GH 10 & $\mathrm{~N}^{\mathrm{e}}$ & 31.213 & 6.89 & 76 \\
\hline 19 & 572 & 7045 & Endo- $\beta-1,4-x y l a n a s e(x y n 10 C)$ & GH 10 & $\mathrm{~N}^{\mathrm{e}}$ & 31.213 & 6.89 & 62 \\
\hline 20 & 1033 & 7045 & Endo- $\beta-1,4-x y l a n a s e(x y n 10 C)$ & GH 10 & $\mathrm{~N}^{\mathrm{e}}$ & 31.213 & 6.89 & 76 \\
\hline 21 & 537 & 7045 & Endo- $\beta-1,4-x y l a n a s e(x y n 10 C)$ & GH 10 & $\mathrm{~N}^{\mathrm{e}}$ & 31.213 & 6.89 & 75 \\
\hline 22 & 428 & 133788 & Endo- $\beta-1,4$-xylanase $(x y n 11 B)$ & GH 11 & $\mathrm{C}$ & 30.811 & 5.72 & 21 \\
\hline 23 & 114 & 133788 & Endo- $\beta-1,4$-xylanase $(x y n 11 B)$ & GH 11 & $\mathrm{C}$ & 30.811 & 5.72 & 17 \\
\hline 24 & 184 & 7048 & Putative endo-xyloglucanase (cel12B) & GH 12 & - & 27.084 & 4.74 & 10 \\
\hline 25 & 179 & 8466 & Endo- $\beta$-1,4-glucanase (cel12A) & GH 12 & - & 26.461 & 4.79 & 19 \\
\hline 26 & 176 & 8466 & Endo- $\beta$-1,4-glucanase (cel12A) & GH 12 & - & 26.461 & 4.79 & 8 \\
\hline 27 & 277 & 29397 & Putative rhamnogalacturonase ( $r g h 28 \mathrm{C})$ & GH 28 & - & 44.801 & 5.22 & 51 \\
\hline 28 & 674 & 29397 & Putative rhamnogalacturonase $(\mathrm{rgh} 28 \mathrm{C})$ & GH 28 & - & 44.801 & 5.22 & 50 \\
\hline 29 & 91 & 4822 & Endo-1,5- $\alpha$-L-arabinanase & GH 43 & - & 33.101 & 4.82 & 9 \\
\hline $30^{\mathrm{f}}$ & & & Endo- $\beta$-1,4-glucanase (cel45) & GH 45 & - & 18.169 & 5.04 & \\
\hline 31 & 595 & 28013 & Glycoside hydrolase family $74(x g h 74 B)$ & GH 74 & - & 66.641 & 4.56 & 44 \\
\hline 32 & 604 & 138226 & Putative xyloglucanase (gly74A) & GH 74 & - & 77.792 & 4.72 & 36 \\
\hline 33 & 973 & 134556 & Xyloglucanase $(x g h 74 B)$ & GH 74 & $\mathrm{C}$ & 89.860 & 5.05 & 43 \\
\hline 34 & 1014 & 134556 & Xyloglucanase $(x g h 74 B)$ & GH 74 & $\mathrm{C}$ & 89.860 & 5.05 & 41 \\
\hline 35 & 123 & 3280 & Thaumatin-like protein (thn2) & & - & 27.768 & 4.74 & 14 \\
\hline 36 & 97 & 3280 & Thaumatin-like protein $(t h n 2)$ & & - & 27.768 & 4.74 & 14 \\
\hline 37 & 240 & 5297 & Thaumatin-like protein $(t h n l)$ & & - & 29.288 & 4.99 & 14 \\
\hline 38 & 143 & 5297 & Thaumatin-like protein $(t h n l)$ & & - & 29.288 & 4.99 & 14 \\
\hline 39 & 697 & 126075 & Putative acetyl xylan esterase (axe 1 ) & CE 1 & - & 35.970 & 5.91 & 29 \\
\hline 40 & 511 & 126075 & Putative acetyl xylan esterase (axe 1 ) & CE 1 & - & 35.970 & 5.91 & 29 \\
\hline 41 & 772 & 126075 & Putative acetyl xylan esterase (axe 1 ) & CE 1 & - & 35.970 & 5.91 & 29 \\
\hline 42 & 391 & 126075 & Putative acetyl xylan esterase (axe 1 ) & CE 1 & - & 35.970 & 5.91 & 29 \\
\hline 43 & 776 & 126075 & Putative acetyl xylan esterase (axe 1) & CE 1 & - & 35.970 & 5.91 & 29 \\
\hline 44 & 275 & 129015 & Carbohydrate esterase family 1 protein (axe 1 ) & CE 1 & $\mathrm{~N}^{\mathrm{e}}$ & 30.753 & 6.20 & 21 \\
\hline 45 & 289 & 129015 & Carbohydrate esterase family 1 protein (axe1) & CE 1 & $\mathrm{~N}^{\mathrm{e}}$ & 30.753 & 6.20 & 13 \\
\hline 46 & 439 & 132137 & Pectin methylesterase & CE 8 & - & 36.287 & 5.84 & 36 \\
\hline 47 & 554 & 130517 & Putative glucuronoyl esterase & CE 15 & $\mathrm{~N}$ & 49.741 & 5.55 & 28 \\
\hline 48 & 245 & 3097 & Fungal cellulose binding domain-containing protein & CE 16 & $\mathrm{~N}$ & 43.216 & 5.08 & 15 \\
\hline
\end{tabular}


Table 1 (continued)

\begin{tabular}{|c|c|c|c|c|c|c|c|c|}
\hline Spot number & Score $^{\mathrm{a}}$ & Protein $\mathrm{ID}^{\mathrm{b}}$ & Function (gene or domain) & Protein family & $\mathrm{CBM}^{\mathrm{c}}$ & $\mathrm{Th} \mathrm{Mw}^{\mathrm{d}}$ & Th $\mathrm{p} I^{\mathrm{d}}$ & $\begin{array}{l}\text { Sequence } \\
\text { coverage } \\
(\%)\end{array}$ \\
\hline 49 & 821 & 11098 & $\begin{array}{l}\text { Iron reductase domain/cellobiose dehydrogenase } \\
(c d h)\end{array}$ & AA8-AA3_1 & - & 82.189 & 5.19 & 31 \\
\hline 50 & 313 & 41563 & Lytic polysaccharide monooxygenase & AA9 & $\mathrm{C}$ & 33.203 & 5.39 & 29 \\
\hline 51 & 301 & 121193 & Lytic polysaccharide monooxygenase & AA9 & $\mathrm{C}$ & 32.562 & 4.31 & 25 \\
\hline 52 & 207 & 138479 & Aldose 1-epimerase (ale 1 ) & & - & 38.454 & 4.98 & 27 \\
\hline 53 & 316 & 8221 & Hypothetical protein (IPR010829 Cerato-platanin) & & - & 14.970 & 4.69 & 33 \\
\hline 54 & 453 & 3085 & Hypothetical protein & & - & 40.214 & 5.02 & 35 \\
\hline 55 & 117 & 2416 & Hypothetical protein & & - & 17.519 & 8.44 & 27 \\
\hline
\end{tabular}

${ }^{\text {a } I n-h o u s e ~ M A S C O T ~ s c o r e ~}$

${ }^{\mathrm{b}}$ Protein model number from the $P$. chrysosporium genome database version 2.0

${ }^{\mathrm{c}}$ Deduced amino acid sequence with and without a carbohydrate binding module (CBM); $N$ N-terminal, $C$ C-terminal

${ }^{\mathrm{d}}$ Theoretical molecular mass (Th $\mathrm{Mw}, \mathrm{kDa}$ ) and $\mathrm{p} I$

${ }^{\mathrm{e}}$ Manual annotation revealed existence of a signal peptide and/or a CBM sequences in the gene

${ }^{\mathrm{f}} \mathrm{MS} / \mathrm{MS}$ dataset of spot number 30 searched against genome version 2.0 in Scaffold 6:1798039-1798139 [29]

Table 2 Increased 2DE spot volumes between ammoniatreated and untreated birch wood meal cultures

\begin{tabular}{llllll}
\hline Spot number & Protein family & Function (gene or domain) & \multicolumn{2}{l}{$\begin{array}{l}\text { Normalized average } \\
\text { volume }\end{array}$} & $\begin{array}{l}\text { Relative } \\
\text { degree }\end{array}$ \\
\cline { 4 - 6 } & & & $\mathrm{UB} \times 10^{7}$ & $\mathrm{AB} \times 10^{7}$ & \\
\hline 36 & & Thaumatin-like protein & 0.13 & 0.64 & 5.0 \\
22 & & Endo- $\beta$-1,4-xylanase (xyn11B) & 0.60 & 2.9 & 4.9 \\
19 & GH 10 & Putative endo- $\beta$-1,4-xylanase (xyn10C) & 0.25 & 1.2 & 4.7 \\
55 & & Hypothetical protein & 0.07 & 0.28 & 4.2 \\
23 & GH 11 & Endo- $\beta$-1,4-xylanase (xyn11B) & 0.12 & 0.52 & 4.2 \\
52 & A1e1 & Aldose 1-epimerase (ale1) & 0.24 & 0.83 & 3.4 \\
38 & & Thaumatin-like protein & 0.09 & 0.27 & 3.0 \\
14 & GH 7 & Cellobiohydrolase 62 (cel7C) (Fragment) & 0.30 & 0.70 & 2.4 \\
24 & GH 12 & Putative endoxyloglucanase (cell2B) & 0.43 & 1.0 & 2.4 \\
13 & GH 7 & Cellobiohydrolase 62 (cel7C) (Fragment) & 1.6 & 3.6 & 2.2 \\
\hline
\end{tabular}

Spots showing a normalized average volume increase by twofold or more on $2 \mathrm{DE}$ gels in AB vs. UB cultures. Spot numbers correspond to those in Fig. 3 and Table 1, and the intensity was analyzed by Prodigy $2 \mathrm{D}$ ver. 1.0. The relative degree calculation equals the normalized average volume of $\mathrm{AB}$ divided by the normalized average volume of UB

$U B$ untreated birch wood meal, $A B$ ammonia-treated birch wood meal of lignin-decomposing enzymes in the culture was precluded. In addition, protease activity was increased 2.2fold in the $\mathrm{AB}$ culture compared to the UB control culture and the 2DE profiles of the $\mathrm{AB}$ culture revealed many low molecular weight proteins, which may be the result of protease-mediated cleavage during cultivation. For example, one of the spots corresponding to a GH family 10 xylanase (Xyn10C) was repressed in the AB culture, while other spots of Xyn10C were enhanced compared to the UB culture. This appeared to be mainly due to proteolytic cleavage of Xyn10C. Therefore, we considered that the total amounts of Xyn10C were essentially the same in the AB and UB cultures.
On the other hand, increased concentration of a GH family 11 xylanase was noted when $\mathrm{AB}$ was used as the carbon source. Notably, GH family 11 xylanase is expressed by various white-rot fungi, including $P$. chrysosporium [33], which is known to secrete three endo-1,4- $\beta$-xylanases. Two xyn genes (xynA and xynC) encode GH family 10 glycoside hydrolases, whereas the third $(x y n B)$ encodes a protein in GH family $11[34,35]$. XynA and XynC, corresponding to Xyn10A and Xyn10C in the present study, also showed activity toward $p$-nitrophenyl- $\beta$-D-cellobioside and $p$-nitrophenyl- $\beta$-D-xylopyranoside, whereas XynB, corresponding to Xyn11B in the present study, hydrolysed only xylan [34]. In addition, XynA and XynC mostly produced 
Table 3 Decreased 2DE gel spot volumes in ammonia-treated vs. untreated birch wood meal cultures

\begin{tabular}{|c|c|c|c|c|c|}
\hline \multirow[t]{2}{*}{ Spot number } & \multirow[t]{2}{*}{ Protein family } & \multirow[t]{2}{*}{ Function (gene or domain) } & \multicolumn{2}{|c|}{ Normalized average volume } & \multirow[t]{2}{*}{ Relative degree } \\
\hline & & & $\mathrm{UB} \times 10^{7}$ & $\mathrm{AB} \times 10^{7}$ & \\
\hline 33 & GH 74 & Xyloglucanase $(x g h 74 B)$ & 0.45 & 0.04 & 0.087 \\
\hline 20 & GH 10 & Putative endo- $\beta-1,4$-xylanase (xyn10C) & 0.92 & 0.12 & 0.14 \\
\hline 34 & GH 74 & Xyloglucanase $(x g h 74 B)$ & 0.81 & 0.17 & 0.21 \\
\hline 27 & GH 28 & Putative rhamnogalacturonase $(\mathrm{rgh} 28 \mathrm{C})$ & 0.14 & 0.04 & 0.30 \\
\hline 49 & AA8-AA3_1 & $\begin{array}{l}\text { Iron reductase domain/cellobiose dehydroge- } \\
\text { nase }(c d h)\end{array}$ & 0.56 & 0.20 & 0.36 \\
\hline 39 & CE 1 & Putative acetyl xylan esterase (axel) & 0.71 & 0.32 & 0.45 \\
\hline
\end{tabular}

Spots showing a normalized average volume decreased by 0.5 -fold or greater on $2 \mathrm{DE}$ gels in $\mathrm{AB}$ vs. UB cultures. Spot numbers correspond to those in Fig. 3 and Table 1, and the intensity was analyzed by Prodigy 2D version 1.0. The relative degree was calculated as the normalized average volume of $\mathrm{AB}$ divided by the normalized average volume of $\mathrm{UB}$

$U B$ untreated birch wood meal, $A B$ ammonia-treated birch wood meal

products resembling xylobiose and xylotetraose, whereas XynB released products resembling xylobiose and xylopentaose [34]. We previously observed a strong induction of Xyn10C in soluble xylan from oat spelt-containing cultures, whereas the production levels of Xyn11B was unaltered [23]. Xylan in oat spelt has $\alpha$-L-arabinose side chains, whereas that in birch wood has additional side chains of 4-O-methyl$\beta$-D-glucuronic acid. Although the lack of response to oat spelt appears to conflict with the results of our present study, a plausible explanation may be that $P$. chrysosporium recognizes changes in the structure of xylan on modification and solubility during ammonia treatment, leading to the enhancement of Xyn11B production. Notably, supplementation with the commercially available GH family 11 xylanase from Neocallimastix patriciarum significantly increased the yields of both glucose and xylose from AB of birch wood [10]. The previous results of enzymatic saccharification show a good correlation with the present results.

Furthermore, ammonia treatment of the biomass reduced the concentration of GH family 74 xyloglucanase (Xgh74B), GH family 28 polygalacturonase (Rgh28C), AA8-AA3 cellobiose dehydrogenase (CDH), and $\mathrm{CE}$ family 1 acetyl xylan esterase (Axe1). Notably, in a previous study, we found that the production of these enzymes was enhanced, rather than reduced, when soluble xylan from oat spelt was added to a cellulolytic culture [23]. These results support the idea that $P$. chrysosporium employs complex, so-far-unidentified mechanisms for recognition of its environment.

In conclusion, we used the comparative secretome analysis to examine the expression levels of proteins secreted by $P$. chrysosporium grown in $\mathrm{UB}$ and $\mathrm{AB}$ cultures. In the $\mathrm{AB}$ culture, relative production of Xyn11B, as a key enzyme for enzymatic saccharification of xylan, was increased. While relative production of $\mathrm{Xgh} 74 \mathrm{~B}, \mathrm{Rgh} 28 \mathrm{C}, \mathrm{CDH}$, and Axe1 decreased. The ammonia pretreatment promoted proteolysis of Xyn10C, leading to a loss of family 1 carbohydrate-binding modules. These results indicated that $P$. chrysosporium produced enzymes related to recognition of structural changes on xylan with de-acetylation and introduction of additional nitrogen by ammonia pretreatment of birch wood meal. However, the complex mechanism that $P$. chrysosporium recognizes and regulates its enzymes is still unknown. Further studies on the enzymatic saccharification of the ammonia pretreated biomass from birch wood using a defined enzyme cocktail from $P$. chrysosporium might provide clues leading to a better understanding of the complex mechanisms of biomass degradation by $P$. chrysosporium, as well as being helpful for optimizing enzyme cocktails for efficient saccharification towards the production of biofuels and biochemicals from lignocellulosic biomass.

Acknowledgements The authors are grateful to Shuichi Mihashi, Reiko Hayashi, and Aiko Akiyama for analysis of the two-dimensional electrophoresis and chemical composition data. This research was supported by: a Grant-in-Aid for Scientific Research (no. 23248025 and 16H04949 to M.S.) from the Japan Society for the Promotion of Science (JSPS). K.I. thanks the Finnish Funding Agency for Innovation (TEKES) for the support of the Finland Distinguished Professor (FiDiPro) Program "Advanced approaches for enzymatic biomass utilisation and modification (BioAD)".

\section{Compliance with ethical standards}

Conflict of interest The authors declare no conflicts of interest associated with this manuscript.

Open Access This article is distributed under the terms of the Creative Commons Attribution 4.0 International License (http://creativeco mmons.org/licenses/by/4.0/), which permits unrestricted use, distribution, and reproduction in any medium, provided you give appropriate credit to the original author(s) and the source, provide a link to the Creative Commons license, and indicate if changes were made. 


\section{References}

1. McNeil M, Darvill AG, Fry SC, Albercheim P (1984) Structure and function of the primary cell walls of plants. Annu Rev Biochem 53:625-663

2. Mosier N, Wyman C, Dale B, Elander R, Lee YY, Holtzapple M, Ladisch M (2005) Features of promising technologies for pretreatment of lignocellulosic biomass. Bioresour Technol 96:673-686

3. Teymouri F, Laureano-Perez L, Alizadeh H, Dale BE (2005) Optimization of the ammonia fiber explosion (AFEX) treatment parameters for enzymatic hydrolysis of corn stover. Bioresour Technol 96:2014-2018

4. Kurosawa M, Kokubo M, Igarashi K, Samejima M (2014) Strategies towards reduction of enzyme cost for ethanol production from cellulosic biomass. J Jpn Inst Energy 93:964-972

5. Yamashita D, Kimura S, Samejima M, Wada M (2016) Effect of ammonia treatment on enzymatic hydrolysis and cell wall components of Erianthus. Polym Degrad Stabil 133:243-248

6. Kumar R, Mago G, Balan V, Wyman CE (2009) Physical and chemical characterizations of corn stover and poplar solids resulting from leading pretreatment technologies. Bioresour Technol 100:3948-3962

7. Chundawat SP, Vismeh R, Sharma LN. Humpula JF, da Costa Sousa L, Chambliss CK, Jones AD, Balan V, Dale BE (2010) Multifaceted characterization of cell wall decomposition products formed during ammonia fiber expansion (AFEX) and dilute acid based pretreatments. Bioresour Technol 101:8429-8438

8. Wada M, Chanzy H, Nishiyama Y, Langan P (2004) Cellulose III crystal structure and hydrogen bonding by synchrotron X-ray and neutron fiber diffraction. Macromolecules 37:8548-8555

9. Igarashi K, Wada M, Samejima M (2007) Activation of crystalline cellulose to cellulose III(I) results in efficient hydrolysis by cellobiohydrolase. FEBS J 274:1785-1792

10. Sakuragi K, Igarashi K, Samejima M (2018) Application of ammonia pretreatment to enable enzymatic hydrolysis of hardwood biomass. Polym Degrad Stabil 148:19-25

11. Broda P, Birch P, Brooks P, Copa-Patiño JL, Sinnott ML, Tempelaars C, Wang Q, Wyatt A, Sims P (1994) Phanerochaete chrysosporium and its natural substrate. FEMS Microbiol Rev 13:189-195

12. Broda P, Birch P, Brooks P, Sims P (1995) PCR-mediated analysis of lignocellulolytic gene transcription by Phanerochaete chrysosporium: substrate-dependent differential expression within gene families. Appl Environ Microbiol 61:2358-2364

13. Broda P, Birch PR, Brooks PR, Sims PF (1996) Lignocellulose degradation by Phanerochaete chrysosporium: gene families and gene expression for a complex process. Mol Microbiol 19:923-932

14. Wymelenberg AV, Sabat G, Martinez D, Rajangam AS, Teeri TT, Gaskell J, Kersten PJ, Cullen D (2005) The Phanerochaete chrysosporium secretome: database predictions and initial mass spectrometry peptide identifications in cellulose-grown medium. J Biotechnol 118:17-34

15. Kersten P, Cullen D (2007) Extracellular oxidative systems of the lignin-degrading Basidiomycete Phanerochaete chrysosporium. Fungal Genet Biol 44:77-87

16. Sato S, Liu F, Koc H, Tien M (2007) Expression analysis of extracellular proteins from Phanerochaete chrysosporium grown on different liquid and solid substrates. Microbiology 153:3023-3033

17. Ďuranová $M$, Špániková S, Wösten HAB, Biely P, De Vries RP (2009) Two glucuronoyl esterases of Phanerochaete chrysosporium. Arch Microbiol 191:133-140

18. Vanden Wymelenberg AV, Gaskell J, Mozuch M, Kersten P, Sabat G, Martinez D, Cullen D (2009) Transcriptome and secretome analyses of Phanerochaete chrysosporium reveal complex patterns of gene expression. Appl Environ Microbiol 75:4058-4068
19. Martinez D, Larrondo LF, Putnam N. Gelpke MD, Huang K, Chapman J, Helfenbein KG, Ramalya P, Detter JC, Larimer F, Coutinho PM, Henrissat B, Berka R, Cullen D, Rokhsar D (2004) Genome sequence of the lignocellulose degrading fungus Phanerochaete chrysosporium strain RP78. Nat Biotechnol 22:695-700

20. Levasseur A, Drula E, Lombard V, Coutinho PM, Henrissat B (2013) Expansion of the enzymatic repertoire of the CAZy database to integrate auxiliary redox enzymes. Biotechnol Biofuels 6:41

21. Abbas A, Koc H, Liu F, Tien M (2005) Fungal degradation of wood: initial proteomic analysis of extracellular proteins of Phanerochaete chrysosporium grown on oak substrate. Curr Genet 47:49-56

22. Ravalason H, Jan G, Mollé D, Pasco M, Coutinho PM, Lapierre C, Pollet B, Bertaud F, Petit-Conil M, Grisel S, Sigoillot JC, Asther M, Herpoël-Gimbert I (2008) Secretome analysis of Phanerochaete chrysosporium strain CIRM-BRFM41 grown on softwood. Appl Microbiol Biotechnol 80:719-733

23. Hori C, Igarashi K, Katayama A, Samejima M (2011) Effects of xylan and starch on secretome of the basidiomycete Phanerochaete chrysosporium grown on cellulose. FEMS Microbiol Lett 321:14-23

24. Johnsrud SC, Eriksson KE (1985) Cross-breeding of selected and mutated homokaryotic strains of Phanerochaete chrysosporium $\mathrm{K}-3$ : new cellulase deficient strains with increased ability to degrade lignin. Appl Microbiol Biotechnol 21:320-327

25. Kremer SM, Wood PM (1992) Evidence that cellobiose oxidase from Phanerochaete chrysosporium is primarily an Fe (III) reductase. Eur J Biochem 205:133-138

26. Lever M (1972) A new reaction for colorimetric determination of carbohydrates. Anal Biochem 47:273-279

27. Hartmann P, Haswell SJ, Grasserbauer M (1994) Monitoring of reducing sugars by flow-injection analysis using $p$-hydroxybenzoic acid hydrazide. Anal Chim Acta 285:1-8

28. Vanden Wymelenberg AV, Minges P, Sabat G, Martinez D, Aerts A, Salamov A, Grigoriev I, Shapiro H, Putnam N, Belinky P, Dosoretz C, Gaskell J, Kersten P, Cullen D (2006) Computational analysis of the Phanerochaete chrysosporium v2.0 genome database and mass spectrometry identification of peptides in ligninolytic cultures reveal complex mixtures of secreted proteins. Fungal Genet Biol 43:343-356

29. Igarashi K, Ishida T, Hori C, Samejima M (2008) Characterization of an endoglucanase belonging to a new subfamily of glycoside hydrolase family 45 of the basidiomycete Phanerochaete chrysosporium. Appl Environ Microbiol 74:5628-5634

30. Gao D, Uppugundla N, Chundawat SP. Yu X, Hermanson S, Gowda K, Brumm P, Mead D, Balan V, Dale BE (2011) Hemicellulases and auxiliary enzymes for improved conversion of lignocellulosic biomass to monosaccharides. Biotechnol Biofuels 4:5

31. Karnaouri A, Matsakas L, Topakas E, Rova U, Christakopoulos P (2016) Development of thermophilic tailor-made enzyme mixtures for the bioconversion of agricultural and forest residues. Front Microbiol 7:177

32. Dass SB, Dosoretz CG, Reddy CA, Grethlein HE (1995) Extracellular proteases produced by the wood-degrading fungus Phanerochaete chrysosporium under ligninolytic and non-ligninolytic conditions. Arch Microbiol 163:254-258

33. Hori C, Gaskell J, Igarashi K, Samejima M, Hibbett D, Henrissat B, Cullen D (2013) Genomewide analysis of polysaccharides degrading enzymes in 11 white-and brown-rot Polyporales provides insight into mechanisms of wood decay. Mycologia 105:1412-1427

34. Decelle B, Tsang A, Storms RK (2004) Cloning, functional expression and characterization of three Phanerochaete chrysosporium endo-1,4-beta-xylanases. Curr Genet 46:166-175

35. Huy ND, Kim SW, Park SM (2011) Heterologous expression of endo-1,4-beta-xylanase $\mathrm{C}$ from Phanerochaete chrysosporium in Pichia pastoris. J Biosci Bioeng 111:654-657 